\title{
Los nacionalismos argentinos: un acercamiento al debate historiográfico en torno a sus figuras de la década de 1930 \\ The Argentine Nationalisms: An Approach to the Historiographic Debate on their 1930s Leading Figures
}

\author{
Gonzalo Rubio García \\ Universidad de Buenos Aires (República Argentina) \\ gonza_rubio@hotmail.com
}

\section{Resumen}

El presente artículo examina las posturas historiográficas con las que distintos historiadores han analizado a los nacionalismos argentinos, haciendo hincapié en las ideas políticas de Raúl Scalabrini Ortiz y en las consideraciones que se han hecho sobre su figura. Se pretende desarrollar una metodología que permita analizar a los nacionalismos como fenómeno cultural, así como mostrar las debilidades y fortalezas de las posturas historiográficas objeto de análisis.

\section{Palabras clave:}

Nacionalismos, Scalabrini Ortiz, anti-imperialismo, revisionismo histórico, historiografía.

\begin{abstract}
In this article we discuss the historiographic interpretations through which different historians have studied Argentine nationalisms. We focus on political ideas of Raúl Scalabrini Ortiz and on the considerations held on him as a writer. Our purpose is to develop a method which allows us to analyze nationalisms as cultural phenomenon, and to show the weaknesses and strengths of the historiographic views object of examination.
\end{abstract}

\section{Key Words}

Nationalisms, Scalabrini Ortiz, anti-imperialism, historical revisionism, historiography. 


\section{Introducción}

La década de 1930 fue uno de los períodos de mayor conflictividad social en Argentina. El impacto de la caída de Wall Street en 1929, seguida de la crisis social y política a principios de la siguiente década, generó una ruptura que perturbó las imágenes construidas -en especial aquellas que mostraban la supuesta excepcionalidad del país- e implicó la revisión de los conceptos e ideologías que articulaban al sistema político. ${ }^{1}$

En dicho contexto de época, cobraron notoriedad distintos intelectuales -Julio y Rodolfo Irazusta, ${ }^{2}$ Ramón Doll y Raúl Scalabrini Ortiz, ${ }^{3}$ entre otros- que reaccionaron frente a lo que consideraban eran políticas económicas y culturales adversas para la Argentina. Se veían a sí mismos como un grupo de escritores surgidos ante la "emergencia nacional" con firme conciencia del desarrollo político, del orgullo patrio y la posición que debía ocupar el país entre las potencias mundiales. ${ }^{4}$

Muchos de los autores nombrados, también caracterizados como nacionalistas, se adhirieron con posterioridad al revisionismo histórico, corriente historiográfica que se destacaba por la común afirmación de todos sus representantes en reivindicarse como rectificadores de la tergiversación de hechos y figuras que habría realizado la "historia oficial", también denominada como "historia mitrista". 5 Destacaban con convencimiento que la Argentina había sido desplazada en 1852 del lugar que la hacía acreedora de su

\footnotetext{
${ }^{1}$ Óscar Terán, Historia de las ideas en la Argentina: Diez lecciones iniciales, 1810-1980 (Buenos Aires: Siglo XXI, 2008), 227.

${ }^{2}$ Los hermanos Irazusta cobraron notoriedad por haber participado en diversas publicaciones nacionalistas en los años 20 y por ser los autores de La Argentina y el imperialismo británico (1934), libro esencial para la historia del revisionismo histórico.

${ }^{3}$ Raúl Scalabrini Ortiz (1898-1959) fue un intelectual argentino que conformó la agrupación FORJA (La Fuerza de Orientación Radical de la Joven Argentina) junto a Homero Manzi y Arturo Jauretche, entre otros.

${ }^{4}$ Clifton Kroeber, Rosas y la revisión de la historia argentina (Buenos Aires: Fondo Editor Argentino, 1964), 34; Tulio Halperín Donghi, El revisionismo histórico como visión decadentista de la historia nacional (Buenos Aires: Siglo XXI, 2005), 16-7. Años más tarde, Fernando Devoto tuvo apreciaciones similares: la mayoría de los estudios han enfatizado sobre todo los vínculos, innegables, entre historia y política que han regido el interés de los revisionistas o han puesto de manifiesto "el carácter ensayístico y la debilidad heurística de sus trabajos". Fernando Devoto, "Introducción" a La historiografía Argentina en el siglo XX (Buenos Aires: Editores de América Latina, 2006), 22.

${ }^{5}$ Véase Pedro De Paoli, El revisionismo histórico y las desviaciones del Dr. José María Rosa (Buenos Aires: Theoria, 1965), 7; José María Rosa, Historia del revisionismo y otros ensayos (Buenos Aires: Editorial Merlín, 1968), 34; Tulio Halperín Donghi, El revisionismo histórico, 17;del mismo autor, Argentina en el Callejón (Buenos Aires: Ariel, 2006), 104, Óscar Terán, Historia de las ideas, 232; José Carlos Chiaramonte, Usos políticos de la historia: Lenguaje de clases y revisionismo histórico (Buenos Aires: Sudamericana, 2013), 174; Fernando Devoto y Nora Pagano, Historia de la historiografía argentina (Buenos Aires: Sudamericana, 2009), 201; y Michael Goebel, La Argentina partida: nacionalismos y políticas de la historia (Buenos Aires: Prometeo, 2003), 17.
}

ISSN 2174-4289 
grandeza por obra de traidores y enemigos. ${ }^{6}$ Aspiraban a regenerar el espíritu argentino quitar al liberalismo y su doctrina "foránea" implantada por Bartolomé Mitre y Bernardino Rivadavia, ${ }^{7}$ entre otros- cambiando radicalmente la vida política nacional. Asumieron la necesidad de construir una visión histórica distinta a la que consideraban falsificada rescatando un pasado que a sus ojos permanecía oculto. ${ }^{8}$

Si seguimos la lógica de la anterior perspectiva, es razonable identificar al revisionismo con el nacionalismo, aunque, desde luego, no todos los nacionalistas fueron revisionistas, así como no todos los revisionistas defendieron el mismo tipo de nacionalismo. ${ }^{9}$ De ese modo, dada la importancia política y la complejidad que supo guardar dicho fenómeno en la historia argentina en torno a la década de 1930, en este trabajo estudiamos las posturas con las que distintos historiadores -Fernando Devoto, José Carlos Chiaramonte, Tulio Halperín Donghi, entre otros- han analizado a los nacionalismos, tomando como principal figura de análisis a Scalabrini Ortiz y en menor medida a los hermanos Irazusta y Manuel Gálvez. Algunas de sus ideas políticas lo alejaban de otros intelectuales nacionalistas, razón por la cual consideramos que el análisis de los estudios que se han realizado sobre Scalabrini Ortiz ayudará a comprender mejor el confuso mundo cultural de la denominada "década infame". 10

Los autores aquí tenidos en cuenta cumplían la función de intelectuales, un término que ha recibido distintos usos desde "el último tercio del siglo XIX". Su papel dentro de ese terreno -por ser hombres de ideas que interpelaba a la opinión pública, mediante discursos y ensayos, con una misión cultural- estaba recortado por la configuración histórica de su tiempo y por aquellos otros intelectuales con los que dialogaban, próximos a analizar en este trabajo. ${ }^{11}$

\footnotetext{
${ }^{6}$ Clifton Kroeber, Rosas y la revisión, 34.

${ }^{7}$ Rivadavia fue el primer jefe de estado de las Provincias Unidas del Río de la Plata (desde el 8 de febrero de 1826 hasta el 27 de junio de 1827), mientras que Mitre fue presidente de la Argentina entre 1862 y 1868 y además se lo considera un intelectual importante para la historia de la historiografía argentina.

${ }^{8}$ Clifton Kroeber, Rosas y la revisión, 46; Michael Goebel, La Argentina partida, 17; y Julio Stortini, "Fervores patrióticos: monumentos y conmemoraciones revisionistas en la historia reciente" en Alejandro Eujanian, Ricardo Pasolini y María Estela Spinelli (eds.), Episodios de la cultura histórica argentina: celebraciones, imágenes y representaciones del pasado, siglos XIX y XX (Buenos Aires: Biblos, 2015 ), 87.

${ }^{9}$ No todos los aportes revisionistas eran bien recibidos por los nacionalistas. Algunos estaban en contra incluso de las posturas nacionalistas de Perón: las posiciones ideológicas e historiográficas de la década de 1940 se presentaban de forma compleja. Véase Tulio Halperín Donghi, El revisionismo histórico, 30-1, Clifton Kroeber, Rosas y la revisión, 43; Alejandro Manuel Cattaruzza, Los usos del pasado (Buenos Aires: Sudamericana, 2007), 163-5; y del mismo autor, Historia de la Argentina, 1916-1955 (Buenos Aires: Siglo XXI, 2009), 153.

${ }^{10}$ Dicho término fue acuñado por José Luis Torres hacia el año 1945 por la corrupción que caracterizó al período en torno a la década de 1930. Véase José Luis Torres, La década infame (Buenos Aires: Editorial de Formación "Patria", 1945), 46-9 y 50-1.

${ }^{11}$ Carlos Altamirano, Intelectuales. Notas de investigación sobre una tribu inquieta (Buenos Aires: Siglo XXI, 2013), 17, 73 y 113-5; Michael Goebel, La Argentina partida, 34; y Antonio Gramsci, Selections from the prison notebooks (Nueva York: International Publishers, 1971), 8. Además, véase el concepto de "elite
} 
Continuando la anterior lógica, circunscribimos el tipo de investigación que pretendemos desarrollar dentro del campo de estudios de la "historia intelectual". La referencia a este término como "campo" no es casual, ya que si bien "inscribe su labor dentro de la historiografía [...] a veces cruza el límite y se mezcla con otras disciplinas". ${ }^{12}$ Entendemos que los aspectos culturales deben analizarse mediante la historia de las ideas, una parte de la historiografía que busca "comprender las ideas y creencias del pasado" -los conceptos, palabras y representaciones sociales- utilizando escritos que restituyan la visión que los seres humanos tenían de su época, ${ }^{13}$ pero siendo precavidos de no caer en anacronismos en el momento de leer las fuentes históricas, pues hay conceptos naturalizados en nuestra vida cotidiana -nación, patria, y muchos otros que podrían funcionar como ejemplos- cuyo significado era distinto en el pasado. ${ }^{14}$

En este punto es necesario hacer referencia a la idea de "influencia intelectual", pues dicha noción es inevitable para cualquier análisis historiográfico. Entendemos que se refiere a la apropiación por parte de los pensadores de distintas posturas que han evaluado y resignificado para generar, a partir de dicha influencia, una nueva concepción sobre diferentes problemáticas. De esta forma, una influencia intelectual no implica necesariamente la reproducción total de una idea, sino la transformación de un pensamiento original. En relación a la metodología planteada, también debemos tener en cuenta los "usos políticos de la historia" que se realizaron mediante el revisionismo histórico. Tal como afirmó Chiaramonte, consideramos que los historiadores revisionistas y nacionalistas utilizaron la historia para librar una batalla política contra la "historia oficial" y el liberalismo político -aunque diferían en los objetivos y figuras que promocionaban-, logrando una versión de la historia nacional "no menos parcial que aquella que criticaban". ${ }^{15}$

Teniendo en cuenta las posturas de los autores analizados, en primer lugar consideramos que el fenómeno nacionalista debe analizarse teniendo en cuenta los constantes cambios ideológicos que sufrían sus representantes y reflexionando sobre el contexto de época en el cual escribieron sus obras. Estos puntos parecen evidentes, pero en la búsqueda de categorizaciones se tiende a relativizar su importancia, cuestión que nos invita a replantear en las próximas páginas el lugar que se le dieron a las variables mencionadas.

intelectual" en Carlos Altamirano, "Introducción general" a Historia de los intelectuales en América Latina. I. La ciudad letrada, de la conquista al modernismo (Buenos Aires: Katz, 2010), 14.

${ }^{12}$ Carlos Altamirano, Para un programa de historia intelectual y otros ensayos (Buenos Aires: Siglo XXI, 2005), 10.

${ }^{13}$ Óscar Terán, Historia de las ideas, 11.

${ }^{14}$ José Carlos Chiaramonte, Usos políticos de la historia, 277; y Paula Bruno, Pioneros culturales de la Argentina: Biografías de una época (Buenos Aires: Siglo XXI, 2011), 5-7.

${ }^{15}$ José Carlos Chiaramonte, Usos políticos de la historia, 260. 
En segundo lugar, consideramos que el tipo de nacionalismo que defendía Scalabrini Ortiz - basado en la participación activa del estado en la economía, no solo como ente regulador, sino también como un agente clave en el control de aquellas empresas y recursos naturales claves para la política nacional- difería del que sostuvieron en un mismo período - mediados de la década de 1930- autores nacionalistas como Julio Irazusta. Este punto es importante para entender sus concepciones políticas y diferenciarlas de aquellas que postulaban otros nacionalistas.

En tercer lugar, afirmamos que en cualquier estudio sobre los nacionalismos es fundamental estudiar la idea de nación que guardaban sus referentes, pues en ese punto es donde encontraremos diferencias y similitudes sustanciales entre sus discursos. En el caso de Scalabrini Ortiz, su nacionalismo, basado en su idea de nación cultural, favorecía la inclusión y participación política de los inmigrantes en la cultura nacional y contradecía aquellas versiones más conservadoras que en este punto relacionaban dicha cultura con el legado hispánico y el catolicismo.

\section{Los nacionalismos}

Consideramos que el nacionalismo argentino, o sus diversas manifestaciones, es decir, nacionalismos, puede rastrearse desde mediados del siglo XIX en la postulación de políticas económicas en torno a la tutela de la Aduana de Buenos Aires. Políticas a su vez expresadas en términos proteccionistas e incluso industrialistas, en desmedro del liberalismo instaurado. Así, es posible encontrarse con referentes como Vicente F. López, ${ }^{16}$ quien criticaba los principios librecambistas que guiaban la política económica en la década de 1870. La polémica culminó en los debates parlamentarios de 1875 y 1876 en torno a la Ley de Aduana, debates que tuvieron acentuada repercusión en su momento. ${ }^{17}$

$\mathrm{Al}$ entrar en la segunda década del siglo XX los grupos de intelectuales se tornaron cada vez más numerosos y aquellas conclusiones meramente económicas de los años precedentes se vieron ampliadas al adquirir, en algunos casos, una perspectiva literaria, ya que sus conclusiones incluyeron reflexiones filosóficas con repercusiones socio-culturales, políticas e ideológicas, a su vez coincidentes con las planteadas por sus contemporáneos europeos. En torno al Centenario, surgieron intelectuales como Ricardo Rojas y Manuel Gálvez que deslegitimizaron las utópicas ideas de las elites políticas argentinas, representadas en su mayoría por Domingo F. Sarmiento y Bartolomé Mitre, entre otros. Rojas, un activo militante de la Unión Cívica Radical (UCR), y Gálvez, fueron cruciales para entender las raíces de la rebelión cultural contra el liberalismo. ${ }^{18}$

\footnotetext{
${ }^{16}$ Vicente F. López (1815-1903) fue un pensador y político argentino electo diputado nacional en 1876 y Ministro de Hacienda en 1890.

17 Para este tema véase José Carlos Chiaramonte, Nacionalismo y liberalismo económicos en Argentina: 1860-1890 (Buenos Aires: Hyspamerica, 1971), 9-24.

${ }^{18}$ Alberto Spektorowski, Autoritarios y populistas. Los orígenes del fascismo en la Argentina (Buenos Aires: Lumiere, 2011), 81.
}

ISSN 2174-4289 
La publicación en 1909 de La restauración nacionalista fue un evento importante para los nacionalistas -en ese momento histórico conocidos también como tradicionalistas. La obra de Rojas suscitó distintas reacciones públicas que destacaron al libro como la clave del anti liberalismo argentino. En especial, criticaba el "anti-nacionalismo" de las escuelas judías y católicas, pues argumentaba que dividían a la sociedad en vez de conformar una identidad nacional. ${ }^{19}$

Gálvez fue quien mejor reunió los rasgos "para una contraposición convencional entre positivismo y anti-positivismo, y para simbolizar la emergencia de una primera generación nacionalista". ${ }^{20}$ En El diario de Gabriel Quiroga (1910) mostró su faceta tradicionalista, basada en un raciocinio sutil y metafísico que no dejaba de lado las preocupaciones sobre la muerte y el materialismo, inquietudes que encontraban respuesta en su defensa del catolicismo. Mientras denostaba al liberalismo individualista, cuyo exponente eran las ciudades que hacían "triste la vida", la religión le ofrecía consuelo eterno. El camino para no caer en la desgracia era, entonces, dejar de lado aquellos ideales -la búsqueda de riqueza y el materialismo- para recuperar "nuestra alma colectiva", que había sido sembrada por la influencia española (católica) y había crecido en los pueblos bajo el "influjo gauchesco por naturaleza fraternal". ${ }^{21}$

Probablemente hayan sido las décadas del 1920 y 1930 las más influyentes al respecto, dado que ya en ese período había distintos grupos de intelectuales, identificados por la nómina de "nacionalistas", que a través del periodismo difundían su ideario: entre otros, Julio Irazusta y Ernesto Palacio. ${ }^{22}$ Sin embargo, la diversidad de nacionalismos ocasionó equívocos por parte tanto de sus analistas como de sus opositores, cuestión que puede detectarse ya desde el comienzo de la Segunda Guerra Mundial, cuando intelectuales y grupos políticos - por ejemplo la Unión Democrática que denunciaba el carácter nazi-fascista del movimiento peronista- los englobaron bajo distintos rótulos que no siempre describían cabalmente sus posiciones políticas. ${ }^{23}$ Aún en la actualidad persiste este equívoco a través del cual se confunde la identificación de grupos nacionalistas y el uso político de distintas figuras clave de la historia argentina. Es precisamente la vigencia

\footnotetext{
${ }^{19}$ Ibid., 82.

${ }^{20}$ Fernando Devoto, Nacionalismo, fascismo y tradicionalismo en la Argentina moderna. Una historia (Buenos Aires: Siglo XXI, 2002), 42-3.

${ }^{21}$ Manuel Gálvez, El diario de Gabriel Quiroga. Opiniones sobre la vida argentina (Buenos Aires: Taurus, 2001), 85-7, 100 y 114-5.

${ }^{22}$ Véase Fernando Devoto y María Inés Barbero, Los nacionalistas (Buenos Aires: Centro Editor de América Latina, 1983), 68-85.

${ }^{23}$ Esto les sucedió a escritores como Scalabrini Ortiz o Julio Irazusta. En Política británica en el Río de la Plata (1940) Scalabrini Ortiz describió su posición: “A nosotros nos importa muy poco de Europa, pero nos importa mucho nuestra propia vida, y por eso debemos cuidar todos los sentimientos que por simple declinación puedan ser usufructuados por los que se empeñan en precipitarnos a la catástrofe". Véase Raúl Scalabrini Ortiz, Política británica en el Rio de la Plata (Buenos Aires: Reconquista, 1940), 279.
}

ISSN 2174-4289 
de los equívocos referidos a las formas de nacionalismo en Argentina lo que nos ha llevado a analizar la historiografía y los debates respectivos sobre este tema.

\section{El nacionalismo argentino de la década de 1930 y sus diferentes facetas}

Los autores que han estudiado este tema pueden ser divididos a grandes rasgos en cuatro grupos: 1) aquellos que establecieron la existencia de dos tipos de nacionalismo en Argentina, uno "restaurador" y otro "popular"; 2) los que evitaron establecer diferencias entre los nacionalistas y los caracterizaron como un movimiento cercano al fascismo; 3) aquellos que plantearon la dicotomía entre el nacionalismo "doctrinario" y el "republicano"; y 4) los autores que teniendo en cuenta las diferentes ideologías se desentendieron de las categorizaciones establecidas para analizar a los nacionalismos.

El primer grupo de historiadores se desarrolló tras la caída del peronismo en $1955{ }^{24}$ Representaban al nacionalismo popular mediante la agrupación anti imperialista FORJA, ${ }^{25}$ cuyos militantes se consideraban parte del "verdadero nacionalismo argentino" y criticaban duramente a la "oligarquía", al mismo tiempo que exigían la restauración de la soberanía popular. Es decir, que postulaban la participación masiva como base política de toda estrategia nacionalista, pues describían a las clases populares como los verdaderos portadores de la nacionalidad y los potenciales instigadores de una revolución. Reivindicaban el legado de Hipólito Yrigoyen y su obra "reparadora", la cual buscaban llevar a la práctica frente a las políticas de la dirigencia "corrompida" y gobernante en la década de $1930 .^{26}$ Los historiadores que estudiaron dicho grupo consideraron que el nacionalismo restaurador no debía ser explicado sin tener en cuenta los modelos políticos conservadores europeos. Para los restauradores, afirmaron, el anti-imperialismo era otro

\footnotetext{
${ }^{24} \mathrm{E}$ l nacionalismo popular fue estudiado por autores que utilizaron distintas denominaciones para describir un mismo fenómeno: Abelardo Ramos denominó a la corriente "nacionalismo democrático", en Jorge Abelardo Ramos, Revolución y contrarrevolución en la Argentina (Buenos Aires: Amerindia, 1957); Navarro Gerassi la llamó "nacionalismo de izquierda", en Marysa Navarro Gerassi, Los Nacionalistas (Buenos Aires: Editorial Jorge Álvarez, 1969); y Hernández Arregui “nacionalismo revolucionario”, en Juan José Hernández Arregui, La formación de la conciencia nacional (1930-1960) (Buenos Aires: Plus Ultra, 1973). También deben considerarse dentro de este grupo otros estudios más recientes: Norberto Galasso, Vida de Scalabrini Ortiz (Buenos Aires: Colihue, 2008); Mark Falcoff, "Raúl Scalabrini Ortiz: the making of an Argentine Nationalist", Hispanic American Historical Review. Duke University Press, 52 (1972): 74-101; y Christian Buchrucker, Nacionalismo y peronismo: La Argentina en la crisis ideológica mundial (1927-1955) (Buenos Aires: Sudamericana, 1987).

${ }^{25}$ La Fuerza de Orientación Radical de la Joven Argentina (FORJA) fue una agrupación política argentina, fundada el 29 de junio de 1935 y disuelta en 1945, que actuó siguiendo los lineamientos políticos del yrigoyenismo.

${ }^{26}$ Hipólito Yrigoyen fue un político argentino, figura trascendental de la Unión Cívica Radical, dos veces elegido presidente por medio del sufragio secreto y obligatorio masculino establecido por la Ley Sáenz Peña de 1912.
}

ISSN 2174-4289 
argumento tendiente a descalificar a la democracia como instrumento de dominación extranjera: se oponían a los resultados del gobierno ejercido por la democracia popular. ${ }^{27}$

A este respecto, consideramos relevante la apreciación que realizó Raúl Larra en Raúl Scalabrini Ortiz, una conciencia argentina (1982) en referencia al nacionalismo restaurador. Allí Larra remarcó que los escritores de Nuevo Orden (periódico nacionalista que recibía aportes intelectuales de Julio Irazusta, Bruno Jacovella y Ernesto Palacio, entre otros) eran los estructuradores más serios de una ideología fascista criolla, ya que enarbolaban un nacionalismo relacionado a Nicolás Chauvin y a Charles Maurras. Mientras que estos autores criticaban a los gobiernos fraudulentos de la década de 1930, aunque sin proponer la eliminación del latifundio y el desarrollo industrial, el nacionalismo popular habíase opuesto al golpe de José F. Uriburu y acompañado la frustrada conspiración del coronel Roberto Bosch. ${ }^{28}$

Fernando Devoto e Inés Barbero complejizaron en 1983 la dicotomía entre los nacionalismos sin abandonar la postura anteriormente expuesta. En esta línea, expusieron que dentro del nacionalismo de "elite" o "restaurador" debían estar incluidos el "nacionalismo clásico o republicano" -representando por el grupo tras La Nueva República-; el "nacionalismo tradicionalista católico" -integrado en este período por el grupo de Criterio- y el "nacionalismo filo fascista" -ejemplificado por los grupos de choque como la "Legión Cívica" y la "Legión de Mayo" -; mientras que el nacionalismo "laico-democrático" -aquel postulado por Ricardo Rojas y Enrique Mosconi- y el "católico popular" -cuyo mayor exponente fue Gálvez- debía ser englobado dentro del "nacionalismo popular". 29

En el año 1987, Daniel Campi amplió la perspectiva del nacionalismo popular al argumentar que había adquirido una óptica hispanoamericana. El nacionalismo conservador, escribió, quedaba encerrado en los "estrechos límites argentinos, o rioplatenses en el mejor de los casos", y con ello se refería a que no era posible ampliar "su concepto de nación hasta hacerlo abarcable a "los pueblos morenos del subcontinente", debido a la matriz elitista y racista de sus exponentes. ${ }^{30}$ Más recientemente, Noriko Mutsuki, filiándose a la definición de los Irazusta como neo-republicanos y siguiendo en gran medida los postulados de Devoto y Barbero, destacó que una diferenciación tajante y perdurable entre estos y los forjistas no era una correcta forma de abarcar el análisis de los nacionalistas. Desde la postura de la autora, ambos coincidían en temas como el anti-

\footnotetext{
${ }^{27}$ Christian Buchruker, Nacionalismo y peronismo, 260-71 y Norberto Galasso, Vida de Scalabrini Ortiz, 926. Goebel también marcó la diferencia que estableció el nacionalismo de FORJA en su época, pero sin ahondar demasiado en detalles. Solo estableció una caracterización general entre "nacionalismo o nacionalistas" como movimientos y el nacionalismo como discurso general. Michael Goebel, La Argentina partida, 20-5 y 72.

${ }^{28}$ Raúl Larra, Etcétera (Buenos Aires: Ánfora, 1982), 133.

${ }^{29}$ Fernando Devoto y María Inés Barbero, Los nacionalistas, 10-11.

${ }^{30}$ Daniel Enrique Antonio Campi, "El nacionalismo hispanoamericano de Raúl Scalabrini Ortiz", Actas del congreso internacional de historia Americana, (1987): 107 (116-114).
} 
imperialismo contra Gran Bretaña y el neutralismo ante la Segunda Guerra Mundial, siendo el modo de plantear estos temas también algo común en esa generación. ${ }^{31}$ La autora marcó la procedencia similar de Scalabrini Ortiz y los Irazusta, incluso el cambio que ambos tuvieron respecto al radicalismo y la confluencia ideológica que mostraron al participar del diario Reconquista. ${ }^{32}$ Sin embargo, en las mismas páginas la autora marcó los matices que tenían los autores -incluso respecto al neutralismo como política de estado- estableciendo distintas categorizaciones. ${ }^{33}$

Siguiendo una lógica similar, Alberto Spektorowski destacó la evolución que desde 1930 ambos tipos de nacionalismo -de izquierda y derecha- realizaron hacia un "orden nacionalista autoritario". Fueron "caras diferentes pero complementarias de una reacción común contra el estilo de modernización de la elite liberal y una tercera vía común que mezclaba motivos modernizantes y nostálgicos". Ambos grupos, afirmó, atacaron al liberalismo, fueron anti-imperialistas y anti-colonialistas, a la vez que buscaban recuperar el caudillismo y el hispanismo. ${ }^{34}$

En conclusión, el nacionalismo popular y el nacionalismo restaurador tenían diferencias muy marcadas. Para distinguir a ambos grupos es imperativo tomar en consideración dos aspectos: la relación que guardaban con los inmigrantes y también el papel que daban al Estado dentro de la economía. Prestando atención a estas dos cuestiones podremos apreciar las diferencias entre los dos grupos. Sin embargo, debemos considerar que su base intelectual era compartida en la mayoría de los casos, ya que todos los intelectuales representaban al nacionalismo argentino a pesar de sus diferencias. Por esta razón, debemos tomar con precaución las categorizaciones, pues el mundo cultural jamás se encuentra definido de forma rígida.

En el segundo grupo ubicamos a aquellos historiadores que no establecieron diferencias entre los distintos tipos de nacionalismo. Desde esta perspectiva, los intelectuales que seguían a Scalabrini Ortiz en FORJA -y también todos los movimientos neutralistas y nacionalistas- eran de carácter filo-fascista y autoritario. José Luis Romero, al igual que Tulio Halperín Donghi y posteriormente Federico Finchelstein, consideraron que el nacionalismo argentino era homogéneo. Para dichos autores, los nacionalistas estaban claramente influenciados por Charles Maurras y Benito Mussolini, se movían en círculos aristocratizantes y minoritarios que buscaban mantener un orden social rígido y explicaban los males argentinos por el abandono de las ideas monárquicas y católicas. ${ }^{35} \mathrm{El}$ nacionalismo argentino, fruto de la evolución interna de la tradición liberal de los grupos

\footnotetext{
${ }^{31}$ Noriko Mutsuki, Julio Irazusta: Treinta años de nacionalismo argentino (Buenos Aires: Biblos, 2004), 196 ,

${ }^{32}$ Ibid., 202-5.

${ }^{33}$ Ibid., 196-218.

${ }^{34}$ Alberto Spektorowski, Autoritarios y populistas, 25.

35 José Luis Romero, Las ideas políticas en Argentina (Buenos Aires: Fondo de Cultura Económica, 1975) 238; y Tulio Halperín Donghi, El revisionismo histórico, 25-8.
}

ISSN 2174-4289 
dirigentes, habría surgido entonces como una réplica local, no solo del fascismo, sino también de las dictaduras conservadoras y militares que surgieron en Europa bajo inspiración fascista. ${ }^{36}$

En particular, Finchelstein destacó que todos los “fascistas de la Argentina, también llamados nacionalistas, crearon una forma latinoamericana específica con una inclinación particularmente argentina". En Italia, afirmó, el lugar donde por primera vez había accedido al poder, se "llamaba 'fascismo italiano', en Alemania 'nazismo' y en la Argentina 'nacionalismo", 37 Según el autor, los "'fascistas nacionalistas' entendían la nación en términos exclusivistas, xenófobos". Para ellos, continuó, "ningún 'foráneo' podía convertirse en parte de la nación". ${ }^{38}$ Autores como Gálvez o Ricardo Rojas habían terminado haciéndose fascistas en la década de 1930, pues en su proyecto nacionalista habrían identificado a los argentinos como "católicos, anticomunistas y cada vez más antiliberales y antisemitas", 39

Consideramos que estos argumentos solo describen a los grupos filo-fascistas o al nacionalismo restaurador. Así, por ejemplo, los últimos autores mencionados -Romero y Halperín Donghi- desconocieron a todo un grupo del nacionalismo argentino que en nuestra opinión debe tenerse en consideración para lograr una conclusión acertada sobre la política argentina del período. ${ }^{40} \mathrm{El}$ problema radica, posiblemente, en que los análisis sobre esta forma de nacionalismo de Romero y Halperín Donghi estaban sesgados por los esquemas y definiciones usuales utilizadas en desmedro del revisionismo histórico. De cualquier forma, consideramos que el nacionalismo fue un fenómeno más amplio, siendo el fascismo un término que cobra poco sentido fuera de la historia italiana de la época. Si bien es indudable que este movimiento tuvo influencia en los grupos políticos argentinos, no podemos adjudicar similitudes esquemáticas a todos los nacionalistas de la década de 1930.

En el tercer grupo ubicamos a la tendencia que diferenció al nacionalismo republicano del doctrinario, caracterizado como "oligárquico" y "filo-fascista". Según Enrique Álvarez Zuleta, los doctrinarios se basaban fundamentalmente en la letra de la constitución nacional, al tiempo que rechazaban las instituciones políticas argentinas que, consideraban, habían sido corrompidas por el liberalismo. Siguiendo a los fascismos europeos, defendían un cambio completo del sistema de representación y de gobierno. Este

\footnotetext{
${ }^{36}$ Tulio Halperín Donghi, Argentina en el callejón, 103-4.

${ }^{37}$ Federico Finchelstein, Orígenes ideológicos de la "guerra sucia" (Buenos Aires: Sudamericana, 2016), 76.

${ }^{38}$ Ibid., 25, 27 y 39.

${ }^{39}$ Ibid., 47.

${ }^{40}$ Antonio Caponnetto contradijo a estos autores al argumentar - bajo duros términos en donde los acusó de aristocratizantes, elitistas, reaccionarios, etc.- que aquella "pintura" en la que se trató de establecer una relación directa entre la militancia fascista, el revisionismo y el nacionalismo no guardaba ningún tipo de relación con la realidad del esquema nacionalista. Ver: Antonio Caponnetto, Los críticos del revisionismo histórico (Buenos Aires: Instituto Bibliográfico Antonio Zinny, 1998), 117 y 122.
} 
cambio podía lograrse, desde su óptica, con un golpe de estado que llevara al poder a un jefe militar capaz de restaurar los valores religiosos del catolicismo tradicional. En cambio, el nacionalismo republicano aceptaba las instituciones políticas argentinas como legítimas y no proponía reformar el régimen de representación. En lugar de juzgar los postulados filosóficos del liberalismo, remarcaban su carácter negativo para el desarrollo del país. ${ }^{41}$

Sin embargo, esta tendencia, tal como correctamente mostraron Devoto y Barbero, solo podemos aceptarla como una subtipología del denominado nacionalismo restaurador, ya que en la obra de Álvarez Zuleta no se encuentra mencionado en qué grupo incluiría a organizaciones como FORJA o al propio Scalabrini Ortiz. ${ }^{42}$ Es probable que el autor exceptuara de su calificación al nacionalismo forjista debido a las dificultades que le generaba para adaptarlo a su esquema teórico. ${ }^{43} \mathrm{Al}$ respecto, Álvarez Zuleta solo afirmó que Scalabrini Ortiz y FORJA habían sido influenciados por las ideas de los hermanos Irazusta, aclarando que no se extendería en su escrito "sobre esta agrupación y su actividad política", pues abundaban los estudios sobre ella. ${ }^{44}$

En último lugar debemos tener en consideración a aquellos autores que, tomando en cuenta las posturas anteriormente establecidas, buscaron establecer un planteamiento metodológico diferente para analizar los nacionalismos. Este fue el caso de Alejandro Cattaruzza, quien consideró a los revisionistas como un grupo de intelectuales que procuró intervenir en "la amplia zona de encuentro entre el mundo cultural, incluyendo en él a las instituciones historiográficas, y la política". ${ }^{45}$ En este sentido, aclaró, el revisionismo cuyos representantes, recordemos, eran mayoritariamente nacionalistas- se dotó de herramientas muy similares a las construidas ya desde el Centenario por otros grupos culturales y asociaciones historiográficas". 46

Tal como mostró el autor, las simpatías que muchos nacionalistas habían manifestado hacia Alemania e Italia en el contexto de época de la Segunda Guerra Mundial hicieron que la figura de Rosas - su héroe indiscutido- se tornara para buena parte del mundo político "un índice confiable de fascismo". 47 Sin embargo, muchos defensores del rosismo habían estado en la filas de la UCR, lejos de los nacionalistas uriburistas. Esta

\footnotetext{
${ }^{41}$ Un autor contemporáneo, Enrique Álvarez Zuleta en El nacionalismo argentino (1975), situó dentro de esta corriente a los hermanos Irazusta y Ernesto Palacio. En cuanto a los grupos que seguían los pasos de los movimientos fascistas europeos, menciona a la "Alianza de la Juventud Nacionalista". Véase Enrique Álvarez Zuleta, El nacionalismo argentino (Buenos Aires: Ediciones La Bastilla, 1975), 358-60.

${ }^{42}$ Ibid., 356.

${ }^{43}$ Véase Marysa Navarro Gerassi, Los Nacionalistas, 112.

${ }^{44}$ Enrique Álvarez Zuleta, Los nacionalistas, 343.

${ }^{45}$ Tal como mostró el autor, "el liberalismo toleraba a los rosistas" y los "forjistas se filiaban con Urquiza", cuestión que muestra la "radical heterogeneidad" que caracterizaba el debate político y cultural de los años treinta. Véase Alejandro Manuel Cattaruzza, "El revisionismo: itinerario de cuatro décadas" en Alejandro Cattaruzza y Alejandro Eujanián (eds.), Políticas de la historia: Argentina 1860-1960 (Buenos Aires: Alianza, 2003), 160.

${ }^{46}$ Ibid., 145-6.

${ }^{47}$ Alejandro Manuel Cattaruzza, Los usos del pasado, 184.
} 
postura implica la desarticulación de los grupos nacionalistas anteriormente expuesta, entendiendo que en dicho fenómeno proliferaban los grises ideológicos, en especial si tenemos en cuenta que muchos de los autores, como Scalabrini Ortiz, eran considerados pro-fascistas por su defensa de la neutralidad política ante el conflicto bélico. ${ }^{48} \mathrm{Su}$ postura no implicaba que existieran otras, como por ejemplo aquella que expresaban los escritores de Crisol o El Pampero, claramente pro-alemanas. ${ }^{49}$ Tampoco fue menor el caso de los hermanos Irazusta, quienes habían apoyada activamente el golpe de Uriburu, pero que tras su desilusión sobre el desarrollo de los acontecimientos, reexaminaron su posición política y el pasado del país en La Argentina y el imperialismo británico (1934).

En este punto es necesario tener en cuenta la postura de María Inés Tato, autora que también buscó desarticular las posturas existentes sobre los nacionalistas. Argumentó que varias agrupaciones han sido objeto de "variadas taxonomías", pero que en muchas ocasiones las clasificaciones generaron "encasillamientos demasiado rígidos" que no lograron dar cuenta de la frecuente circulación de "dirigentes y militantes entre las diferentes opciones organizativas del universo nacionalista, ni de la habitual cooperación entre ellas, ni de sus elementos comunes". 50

Siguiendo dicha lógica, afirmó que el fascismo italiano, "al calor del ascenso del nazismo, comenzó a perfilarse como un paradigma a imitar, tanto en Europa como fuera de ella", pero que, sin embargo, al desarrollarse la década de 1930, esos paradigmas fueron matizándose, cuestión que explica el "viraje de los Irazusta, de Palacio, de Gálvez, de Ramón Doll, coincidente con la reivindicación efectuada por FORJA”. Si en el pasado cercano los nacionalistas mencionados se habían entendido con los antiguos grupos conservadores, los últimos luego prescindieron de su colaboración política. ${ }^{51}$ Entonces, los límites entre conservadores y nacionalistas fueron tan permeables y porosos como aquellos que había entre los grupos por otros autores denominados como "nacionalistas populares" y "nacionalistas conservadores". 52

${ }^{48}$ Cattaruzza ha descrito la década de 1930 como una época en donde no podían distinguirse "ni un enfrentamiento que articule todo el escenario, ni dos claros y precisos adversarios que lo protagonicen”. El panorama se presentaba, entonces, "confuso, complejo y múltiple". Ver: A. M. Cattaruzza, Historia de la Argentina, 136.

${ }^{49}$ María Inés Tato, "El ejemplo alemán. La prensa nacionalista y el tercer Reich”, Revista 6, vol. 1, 6 (2007): 52 (33-61).

${ }^{50}$ María Inés Tato, "Nacionalistas y conservadores, entre Yrigoyen y la década infame” en Lilia Ana Bertoni y Luciano De Privitellio (eds.), Conflictos en democracia: La vida política argentina entre dos siglos (Buenos Aires: Siglo XXI, 2009), 158.

${ }^{51}$ Ibid., 162-5.

${ }^{52} \mathrm{Al}$ respecto, si bien se ha relacionado al peronismo con el nacionalismo y el revisionismo, el ex presidente Juan Domingo Perón tuvo en su gobierno gestos con los enemigos de esa corriente historiográfica. Incluso, gran cantidad de funcionarios del movimiento peronista elegía la historiografía tradicional y no eran revisionistas. Según Tulio Halperín Donghi, los nombres elegidos para denominar a los ferrocarriles hablaban de la impronta historiográfica que seguía el gobierno. Afirmó que el triunfo peronista pudo debilitar el influjo de la "historia oficial" en los centros oficiales de estudios históricos, pero que, sin embargo, no se tradujo en la integración de la óptica revisada del pasado argentino, pues Perón no recibió el aporte revisionista con 


\section{Divergencias en torno a la posición política de Scalabrini Ortiz}

Distintos autores argumentaron posiciones contrapuestas en referencia a la postura política de Scalabrini Ortiz. En este apartado expondremos sus opiniones y la base teórica sobre la cual sustentaron sus ideas, teniendo en cuenta las nociones de nacionalismo mencionadas previamente.

En primer lugar, distintos historiadores han analizado a Scalabrini Ortiz como un integrante del nacionalismo popular, ya que buscaba diferenciarse de los grupos más conservadores. De manera que, un punto fundamental en que se basaron para ubicar allí a nuestro intelectual fue la concepción que tenía sobre los inmigrantes, ya que en sus obras hay claras referencias a su propuesta de integrarlos tanto social como culturalmente. ${ }^{53}$ Esta característica lo distanció de los autores pertenecientes al nacionalismo restaurador que insistían en el rechazo a los "agentes externos". A continuación mencionaremos las obras más relevantes sobre quienes consideraron a Scalabrini Ortiz desde esta perspectiva.

En la biografía Vida de Scalabrini Ortiz (1970), Norberto Galasso afirmó que, al menos desde 1933, Scalabrini Ortiz trató de combatir a los nacionalismos conservadores. Sin embargo, aclaró que la "superestructura ideológica al servicio del imperialismo" buscó relacionarlo con la derecha "fascista o nazi". ${ }^{54}$ Para él, esta estrategia articulada por los "agentes británicos" servía para que las masas carecieran de una alternativa al

efusión. El rosismo, destacó Alejandro Cattaruzza, "no formaba parte del conjunto de posiciones oficiales compartidas por el peronismo, proclive en cambio a instalarse en una tradición más clásica". Como bien ha mostrado Julio Stortini, Perón no estaba interesado en abrir un "frente de combate historiográfico con una oposición que ya lo venía comparando con la tiranía rosista". De esta forma, si bien el peronismo fue apoyado por muchos nacionalistas, como José María Rosa, e incluso utilizó para su ideario muchas de sus reivindicaciones, el Instituto Nacional de Investigaciones Históricas Juan Manuel de Rosas -reducto que contenía a muchos nacionalistas y revisionista de trascendencia como Julio Irazusta y Julio C. Corvalán Mendilaharsu- padeció la falta de apoyo oficial. Incluso el autor aclaró que, según J. M. Rosa, los proyectos para repatriar los restos de Rosas fracasaron a causa de Perón, quien no quería dividir al peronismo. Estas cuestiones nos muestran la forma intrincada en que se presentaba el mundo cultural de la década de 1940. Véase Diana Quattrocchi-Woisson, Los males de la memoria: Historia y política en la Argentina (Buenos Aires: EMECE, 1995), 291; Julio Stortini, "Historia y política. Producción y propaganda revisionista durante el primer peronismo" en Alejandro Cattaruzza y Alejandro Eujanián (eds.), Políticas de la historia: Argentina 1860-1960 (Buenos Aires: Alianza, 2003), 233; Tulio Halpherín Donghi, El revisionismo histórico, 30-1; Clifton Kroeber, Rosas y la revisión, 43; Alejandro Manuel Cattaruzza, Los usos del pasado (Buenos Aires: Sudamericana, 2007), 163-5; y del mismo autor, Historia de la Argentina, 153.

${ }^{53}$ Véase Raúl Scalabrini Ortiz, El hombre que está solo y espera (Buenos Aires: Albatros, 1951), 11-3.

${ }^{54} \mathrm{La}$ gran mayoría de autores que realizaron una reivindicación política de Scalabrini Ortiz remarcaron este aspecto. Véase Juan Carlos Jara, Brizna de multitud: vida y pensamiento de Raúl Scalabrini Ortiz (Buenos Aires: Ediciones Instituto Superior Dr. Arturo Jauretche, 2009), 11; Ana Jaramillo, "Presentación" a Forjando una nación: Scalabrini Ortiz y Jauretche en la revista 'Que sucedió en siete días', (Buenos Aires, Ediciones de la UNLA, 2006), 16; y René Orsi, Jauretche y Scalabrini Ortiz (Buenos Aires: Peña Lillo, 1985), 14.

ISSN 2174-4289 
liberalismo. ${ }^{55}$ Tanto en la obra de Galasso, como en la de otros autores que realizaron una reivindicación política del autor, ${ }^{56}$ se mostró a Scalabrini Ortiz como un intelectual profundamente comprometido con los sufrimientos de sus compatriotas y con la liberación económica, política y cultural argentina. ${ }^{57}$

Mark Falcoff también ubicó a Scalabrini Ortiz dentro del nacionalismo popular. Sin embargo, en su artículo de 1972 analizó las raíces intelectuales de nuestro autor concluyendo que las influencias que había recibido en su contexto familiar estaban relacionadas al liberalismo, el positivismo y la masonería, algo común entre los miembros de la elite terrateniente. ${ }^{58}$ Scalabrini Ortiz había desarrollado un incipiente nacionalismo burgués adecuado al momento de crisis en una economía orientada al predominio de la exportación. ${ }^{59}$ Probablemente, argumentó, este fuera uno de los principales motivos que lo llevaron a acercarse a los sectores más nacionalistas del radicalismo, pues representaban un movimiento de protesta, principalmente, contra la "oligarquía" argentina. ${ }^{60}$

Es posible que militando en FORJA, Scalabrini Ortiz haya recibido influencias ideológicas de la Unión Cívica Radical. Ello puede verse reflejado en la coincidencia temática en cuestiones como el problema del petróleo, la defensa de la neutralidad durante la Segunda Guerra Mundial o el rescate de ciertos elementos culturales autóctonos. ${ }^{61}$ Dos representantes destacados de esta corriente nacionalista fueron Manuel Ortiz Pereyra y Enrique Mosconi. La importancia de Mosconi para el grupo FORJA radicó "en su reivindicación del nacionalismo económico desde una perspectiva industrialista y en la defensa del capital nacional estatal y privado". 62 A su vez, Ortiz Pereyra marcó directamente al grupo FORJA por ser un precursor en la tarea de denunciar la dependencia cultural y económica en que veía sumergida a la Argentina de la Belle Époque.

Scalabrini Ortiz concebía al Estado como un ente promotor, gestor y regulador de la vida económica capaz de ejercer la independencia política frente a las potencias europeas. ${ }^{63}$

\footnotetext{
${ }^{55}$ Norberto Galasso, Vida de Scalabrini Ortiz, 153-5.

${ }^{56}$ Uno de los mayores exponentes de esta idea fue Juan Carlos Jara, quien no ahorró críticas ni agravios hacia Cattaruzza, Rodríguez, Romero y Halperín Donghi. Lo que unió a todos estos autores -y a otros- según él, fue la incomodidad cultural y política que les generó Scalabrini Ortiz. Jara describió teorías conspirativas de carácter político muy difíciles de probar. Véase Juan Carlos Jara, Brizna de multitud, 26, 41 y 38.

${ }^{57}$ Debemos resaltar el papel que dio Orsi a la "intellegentzia": Scalabrini Ortiz buscaba "alejarse de ellos y lo que entendían por una vida triunfal”. Véase René Orsi, Jauretche y Scalabrini Ortiz, 19 y 60.

${ }^{58}$ Mark Falcoff, "Raúl Scalabrini Ortiz”, 79.

${ }^{59}$ Ibid., 98.

${ }^{60}$ Enrique Bares hizo una breve mención sobre el tema en su biografía de 1961. Véase Enrique Bares, Scalabrini Ortiz: el hombre que estuvo solo (Buenos Aires: Peña Lillo, 1961), 12.

${ }^{61}$ Fernando Devoto y María Inés Barbero, Los nacionalistas, 126.

${ }^{62}$ Ibid., 129.

${ }^{63}$ Otros autores también hicieron hincapié en la integración teórica que estableció Scalabrini Ortiz respecto a los inmigrantes y las propuestas para restablecer la soberanía política nacional mediante el desarrollo de la industria. Véase Christian Buchrucker, Nacionalismo y peronismo, 260-70; Marck Falcoff, "Raúl Scalabrini Ortiz”, 77-9, Fernando Devoto y Nora Pagano, Historia de la historiografía argentina, 222 y 232; Fernando
} 
Había otros intelectuales que sostenían la necesidad de ejercer políticas económicas proteccionistas como las propuestas por el nacionalismo radical, pero ninguno de ellos vinculaba su programa, tal como hacía Scalabrini Ortiz, con "la necesidad de quebrar el predominio oligárquico en el manejo del Estado como condición necesaria de la industrialización". 64

Sin embargo, debemos matizar dicho acercamiento político ya que Scalabrini Ortiz nunca se afilió a la UCR. Quizá simpatizaba con algunas de las medidas tomadas en los gobiernos radicales -sobre todo las que hacían referencia a la defensa de la soberanía política- pero nunca se comprometió por completo con este partido. ${ }^{65} \mathrm{~A}$ su vez, autores como Galasso y Jara trataron de matizar las influencias que había recibido del liberalismo y el positivismo. Consideramos que esta intención responde a la imagen política que buscaron construir sobre Scalabrini Ortiz, ya que el revisionismo nacionalista valoriza negativamente a esas dos corrientes filosóficas. De todas formas, no descartamos la importancia que pudo haber dado a otras tendencias ideológicas. Por estas razones, es necesario establecer con mayor precisión la influencia que tuvieron en nuestro autor algunas figuras del radicalismo.

Otro autor que marcó las distintas opciones políticas que tenían los nacionalistas fue Fernando Devoto. Este acercó la posición política de Scalabrini Ortiz con la de otros nacionalistas reaccionarios, aunque destacando también sus diferencias, tal como observamos anteriormente. Al analizar las influencias intelectuales que recibió nuestro autor, expuso la relación que guardaba con Julio Irazusta: su interpretación era "en varios aspectos perceptible como complementaria de los Irazusta", aunque también era en muchos aspectos "francamente contrapuesta". Si bien en un primer momento estableció una escisión entre estos autores, luego afirmó, sin profundizar demasiado en la cuestión, que Scalabrini Ortiz estaba "en un plano más cercano a las inquietudes de los Irazusta" .6 "Sin embargo, no sería correcto asimilar por completo la postura de Devoto a la de autores como Halperín o Romero por las cuestiones expuestas en el apartado anterior. De todas formas, debemos resaltar que las explicaciones que brindaron todos los historiadores para ubicar a Scalabrini Ortiz dentro del nacionalismo popular fueron básicamente las mismas. ${ }^{67}$

En segundo lugar debemos mencionar la postura de Cattaruzza. Dicho autor, como mencionamos anteriormente, buscó deslindar las categorizaciones establecidas sobre los

Devoto y María Inés Barbero, Los nacionalistas, 125-33; y Daniel Enrique Antonio Campi, "El nacionalismo hispanoamericano", 113-6.

${ }^{64}$ Ibid., 111.

${ }^{65}$ Sobre este punto, Alejandro Cattaruzza y Fernando Rodríguez destacaron el pensamiento republicano y "vagamente liberal democrático" de Scalabrini Ortiz en la década de 1930. Aclararon que su crítica sobre la realidad social no distaba de la realizada por la sociedad en general. Véase Alejandro Manuel Cataruzza y Fernando Rodríguez, "Prefacio" a El hombre que está solo, 26-27.

${ }^{66}$ Fernando Devoto y Nora Pagano, Historia de la historiografía argentina, 222 y 232.

${ }^{67}$ Sobre todo se debe tener en cuenta la integración de los inmigrantes a la cultura nacional, su lucha contra el imperialismo y a favor de la nacionalización de los ferrocarriles.

ISSN 2174-4289 
nacionalismos. En dicha búsqueda, acercó la posición de Scalabrini Ortiz a la de la agrupación FORJA, pero evitó categorizarlos dentro del nacionalismo argentino: ubicó a los nacionalistas - quizá en tanto movimiento- como Irazusta cerca de la órbita política de los integrantes de FORJA, pero ajenos a ella. ${ }^{68}$ No hemos encontrado explicación para dicha distinción, pero es posible que haya surgido mediante el análisis de las agrupaciones políticas a las que pertenecían los autores tenidos en cuenta para este trabajo antes que a sus ideologías, distintas, pero no mucho más que las de otros nacionalistas. ${ }^{69}$ Visto de esta forma, parecería ser que los forjistas poco tenían que ver con el nacionalismo. ${ }^{70}$

Cattaruzza reconoce a Scalabrini Ortiz como una figura clave de FORJA. ${ }^{71}$ Sin embargo, su procedencia no estaba en el radicalismo. Más bien todo lo contrario, pues había sido crítico de las políticas yrigoyenistas y apoyado en un comienzo el golpe de Uriburu -quizá por su cercanía con los hermanos Irazusta- teniendo en cuenta, además, que nunca se afilió a la UCR. ${ }^{72}$ Insistimos en la necesidad de establecer un análisis exhaustivo y pormenorizado de los autores para comprender su ideología y evitar las generalizaciones, pues hay sobrados ejemplos de los errores en los que se incurre al obrar así.

En tercer lugar, hubo historiadores que relacionaron a Scalabrini Ortiz con los grupos fascistas argentinos. Por lo general, los escritores de esta tendencia investigaron las similitudes entre los nacionalistas y no sus diferencias. Este fue el caso de Romero, quien en Las ideas políticas en Argentina, buscó asimilar a Scalabrini Ortiz con los nacionalistas reaccionarios: como mencionamos anteriormente, él consideraba que todos los nacionalismos compartían las mismas características. A pesar de esa cuestión, debemos resaltar que Romero determinó la existencia de un nacionalismo relacionado al radicalismo. Sin embargo, según afirmaba, allí también predominaban "los grupos filofascistas que seguían a Raúl Scalabrini Ortiz". ${ }^{73}$

Tulio Halperín mostró una postura insegura ante el nacionalismo de Scalabrini Ortiz. Sus vacilaciones partieron del concepto restringido y simplista que postuló sobre los

\footnotetext{
${ }^{68}$ Alejandro Manuel Cataruzza, Historia de la Argentina, 79, 150-1 y 155.

69 Alejandro Manuel Cataruzza, "El revisionismo: itinerario de cuatro décadas", 160.

${ }^{70}$ Ana Virginia Persello analizó las divisiones que se generaron dentro de la UCR en la década de 1930. Algunos de sus militantes se alejaban del partido para luego retornar o alejarse definitivamente, como sucedió con algunos forjistas en 1940. Al mismo tiempo, Susana Brauner estudió a aquellos grupos que, sin abandonar las filas radicales (Arturo Frondizi, Luciano Catalano, Eduardo Giuffra, entre otros), buscaron definir al Partido bajo la idea de libertad política e igualdad económica siguiendo las posturas de Yrigoyen e incluso radicalizándolas en torno a las nacionalizaciones y la defensa de la economía Argentina frente a los atropellos del imperialismo. Véase Ana Virginia Persello, Historia del radicalismo (Buenos Aires: Edhasa, 2007), 105; y Susana Brauner, "Yrigoyenistas, Nacionalismo y Justicia Social. Entre el derrocamiento del Presidente H. Yrigoyen y la construcción del peronismo (1930-1945)", 173-5, https://slidedoc.es/yrigoyenistas-nacionalismo-y-justicia-social [consulta 2 junio 2017].

${ }^{71}$ Alejandro Manuel Cattaruzza, Historia de la Argentina, 124.

${ }^{72}$ Raúl Scalabrini Ortiz, El hombre que está solo, 90-2; y Norberto Galasso, Vida de Scalabrini Ortiz, 101-3.

${ }^{73}$ José Luis Romero, Las ideas políticas en Argentina, 238.
} 
nacionalismos, pues no logró definir un lugar político en donde poder ubicar a nuestro autor. Por esta razón, destacó que era un revisionista atípico -Scalabrini Ortiz tendría menos que ver con el modelo de "la derecha francesa" y más con el "hispanoamericanismo de entreguerras"-. Su ambivalencia quedó al descubierto cuando, al hablar sobre José María Rosa y mostrar sus puntos de referencia políticos con el fascismo, estableció que este autor colocaba sus construcciones históricas muy cerca de las de Scalabrini Ortiz. Como ya hemos señalado, Halperín Donghi, a diferencia de otros autores, no hizo ningún tipo de distinción política entre los nacionalistas. La estructura teórica de su análisis no le permitió, en nuestra opinión, diferenciar correctamente la posición política de los representantes más importantes del revisionismo histórico y el nacionalismo. ${ }^{74}$

Siguiendo la lógica de Halperín, Finchelstein destacó que Scalabrini Ortiz “introdujo una versión de izquierda y populista del nacionalismo que coincidía en parte con muchos de los postulados de sus compañeros nacionalistas y se apartaba de otros". Incluso afirmó la identidad criolla "potencialmente inclusiva" de nuestro autor. Sin embargo, destacó su colaboración en publicaciones fascistas y nazis alemanas, argumentando también que el diario Reconquista - cuyo director era Scalabrini Ortiz- recibió subsidios de la Alemania nazi y colaboraciones intelectuales de nacionalistas antisemitas, acompañando al Eje ante la "cruzada contra las democracias liberales". ${ }^{75}$

Desde nuestra perspectiva consideramos que las diferencias entre los hermanos Irazusta, Gálvez y Scalabrini Ortiz, eran muy marcadas, máxime en relación a sus concepciones sobre lo que debía representar la nación (cuestión de vital importancia para analizar los nacionalismos). Sin embargo, entendemos que en ciertos puntos había algunas similitudes teóricas. Podría decirse que la base de su pensamiento tuvo puntos en común la amistad que mantenían y los círculos sociales que frecuentaban parecen haberlos acercado ideológicamente-, pero que el desarrollo y puesta en práctica de sus ideas fue totalmente diferente. Por esta razón, consideramos que este punto merece un análisis pormenorizado para lograr una acertada conclusión sobre la posible similitud que tenían las posturas políticas de Scalabrini Ortiz con las de otros nacionalistas.

\section{Conclusión}

Los intelectuales nacionalistas sufrieron distintos cambios en su ideología a lo largo de la historia. Dicha evolución fue usual entre quienes vivieron los vaivenes económicos y políticos -nacionales e internacionales- en la Argentina de principios del siglo XX. Basta con tomar en cuenta las figuras de Gálvez o los hermanos Irazusta para comprender que sus apreciaciones a finales de la década de 1920 no eran del todo similares a las que supieron guardar una década más tarde. En el caso de Irazusta, en el término de unos pocos años, pasó de luchar contra Yrigoyen -incluso tuvo un profundo debate con Gálvez sobre

\footnotetext{
${ }^{74}$ Tulio Halpherín Donghi, El revisionismo histórico, 26 y 34.

${ }^{75}$ Federico Finchelstein, Orígenes ideológicos, 56-7 y 153.
} 
su figura- a incorporarse a la UCR en 1937 (aunque el candidato era Marcelo T. de Alvear). ${ }^{76}$

Como hemos podidos observar, distintos autores han tratado de encuadrar a los nacionalistas siguiendo sus posturas ideológicas. Desde nuestra perspectiva consideramos que se debe deslindar el camino transitado, pues las categorizaciones no han logrado más que confundir el estudio del nacionalismo argentino bajo clasificaciones simplistas. Es probable que las consideraciones deban tomarse individualmente, haciendo hincapié en la ideología de cada autor y teniendo en cuenta, además, sus influencias intelectuales. No negamos la similitud de posturas que tuvieron los nacionalistas. Pero, teniendo en cuenta el análisis anteriormente expuesto, se torna evidente que los límites ideológicos no estaban esquemáticamente planteados: dependiendo del contexto de época -factor esencial para cualquier análisis histórico- los autores que gravitaron en torno al nacionalismo mostraron puntos en común y discrepancias. Un estudio sobre las particularidades que guardaban generaría un cúmulo de información que podría favorecer un entendimiento cabal de este fenómeno.

Sin caer en clasificaciones esquemáticas, autores como Tato o Cattaruzza han estudiado a los nacionalistas desde los grupos intelectuales a los que concurrían -FORJA, en el caso de las agrupaciones, y Nuevo Orden, Reconquista, Crisol, entre otros, en el caso de los periódicos en los que escribían-, postura que no consideramos desacertada, pero quizá incompleta, pues en muchos casos dichos grupos no reflejaban las particularidades intelectuales de cada autor. El nacionalismo, como postura política, circunscribe al conjunto de pensamientos que tuvieron los pensadores de cada época histórica, idea que implica la posibilidad de encontrar tantos nacionalismos como intelectuales se hayan adherido a dicha ideología. Algo similar sucede con la idea de nación cultural que sostenían los intelectuales, tal y como hemos podido apreciar con los casos de los Irazusta y Scalabrini Ortiz. Dicho concepto, ya sea considerando al nacionalismo como engendro de la idea de nación o a la inversa, es esencial para entender sus posturas ideológicas y los pensamientos que guardaban sobre los inmigrantes y su incidencia en la sociedad.

La relación política y afectuosa que tuvieron Julio Irazusta y Scalabrini Ortiz es bastante esclarecedora en este punto, y aunque ambos fueron críticos del gobierno de Yrigoyen a principios de la década de 1930, luego defendieron ideas de gobierno disímiles. Pocos años después cambiaron su postura nuevamente ante el contexto de época de la Segunda Guerra Mundial. Finalmente, con la llegada del peronismo, ambos autores tomaron distancia ante un movimiento que obligó a tomar partido frente a las ideologías de la época. ${ }^{77}$ En este sentido, la postura de Cattaruzza parecería ser la más sensata: tal como

\footnotetext{
${ }^{76}$ Noriko Mutsuki, Julio Irazusta, 61.

77 Julio Irazusta escribió una anécdota muy interesante de su relación con Scalabrini Ortiz: "La intimidad a que llegamos fue tan grande que en uno de esos años anteriores al diluvio [refiere al peronismo] que nos separó, hubo una época en que emprendimos juntos, en su casa, la traducción del libro de Rippy sobre la
} 
afirmó el autor, había puntos de encuentro entre los nacionalismos -el afamado "gris" ideológico-que las categorizaciones establecidas no han tomado en cuenta.

Además, debemos considerar que los revisionistas-nacionalistas (relación noexcluyente) no estaban lejos de los círculos académicos en la década de 1930. De esta forma fue posible que Emilio Ravignani tuviera un acercamiento epistolar con Julio Irazusta, pues no fue del todo crítico con su obra publicada en 1934. Sin embargo, la búsqueda por diferenciarse de los supuestos "falsificadores de la historia" y su liberalismo se tornó más importante, al parecer, a principios de la década de 1940. Así se entiende que autores como Atilio García Mellid hablaran de aquellos historiadores como Ernesto Quesada o Estanislao Zeballos quienes, afirmaba, habían buscado desarmar la "historia oficial" de índole mitrista y eurocentrista, característica que incluso había compartido "un historiador de mentalidad oligárquica como Emilio Ravignani”. ${ }^{78}$

El caso de Scalabrini Ortiz debemos tomarlo, entonces, como un ejemplo importante de las diferentes posturas nacionalistas que existieron en la década de 1930. Dicho autor se había deslindado del experimento uriburista rápidamente, camino que los hermanos Irazusta no transitaron hasta bien entrado el año 1933. Aún es más, ambos autores compartieron, al igual que Gálvez, ideas anti-imperialistas que explicaban la decadencia argentina del período a partir de la injerencia inglesa en la política nacional, patrocinada por las oligarquías imperialistas que había permitido dicho sometimiento. Sin embargo, si nos atenemos a las políticas nacionalistas que sostenían, Julio Irazusta tuvo una matriz ideológica liberal a principios de la década de 1930 y no defendió iniciativas estatistas como las de Scalabrini Ortiz y, en menor medida, las de Gálvez. ${ }^{79}$

Scalabrini Ortiz sostuvo una política principalmente latinoamericanista -a la cual también Gálvez se adhirió hacia finales de la década de 1930, luego de haberse acercado al tradicionalismo católico e hispánico a principios del siglo $\mathrm{XX}$ - que era inclusiva con los inmigrantes y que postulaba la unión de la región para luchar contra el imperialismo extranjero. ${ }^{80}$ Además, a diferencia de los Irazusta, Scalabrini Ortiz defendía la nacionalización de los ferrocarriles, así como de otros recursos naturales estratégicos. Es posible que dichas ideas las haya adquirido de autores como Manuel Ortiz Pereyra y Carlos

rivalidad de Estados Unidos e Inglaterra en América Latina”. Julio Irazusta, "Un renovador del Pensamiento Nacional", Clarín (Argentina), 1 de abril de 1976.

${ }^{78}$ Atilio García Mellid, Montoneras y caudillos en la historia argentina (Buenos Aires: Eudeba, 1985) 11, 27, 31, 37, 43, 56 y 63; Julio Irazusta, Vida política de Juan Manuel de Rosas a través de su correspondencia. El Advenimiento de Rosas. Tomo I, Primera Parte, 1793-1830 (Buenos Aires: Albatros, MCMMLIII) 3b; y Julio Irazusta, Memorias: historia de un historiador a la fuerza (Buenos Aires: Ediciones Culturales Argentinas, 1975), 214.

${ }^{79}$ Noriko Mutsuki, Julio Irazusta, 86; y N. Galasso, Vida de Scalabrini Ortiz, 223.

${ }^{80}$ Este tema fue investigado en: Gonzalo Rubio García, "El concepto de nación en Scalabrini Ortiz: acercamientos y diferencias de un nacionalista con los intelectuales de su época", Revista de Historia, 17 (noviembre 2017), 56-82, http://revele.uncoma.edu.ar/htdoc/revele/index.php/historia/index [consulta 2 abril 2017].

ISSN 2174-4289 
D’Amico, aunque lo seguro es que no era afín a los escritos de Charles Maurras y Edmund Burke, escritores que Julio Irazusta ha valorado como parte de su inspiración intelectual. ${ }^{81}$

Luego de las consideraciones aquí realizadas, podemos afirmar que hubo momentos históricos -el golpe de Estado de 1930, el pacto Roca-Runciman, la Segunda Guerra Mundial y la llegada del peronismo- que tuvieron incidencia en las ideas de los nacionalistas y, al mismo tiempo, sirvieron para diferenciar sus posiciones políticas. Sin embargo, no fue hasta 1955 que -de nuevo, y a raíz de un hecho tan trascendente como fue el golpe del 16 de septiembre- las posturas quedaron mayormente definidas. Este fue de hecho el contexto en el que tuvo lugar la conversión de Perón al revisionismo, con su obra Los vendepatrias (1957). Allí, tomó parte de la lógica cultural planteada por los revisionistas -San Martín, Rosas, Yrigoyen y Perón-, mostrándose partícipe de la tradición histórica en que algunos autores como Scalabrini Ortiz lo habían introducido.

Debemos considerar, entonces, algunos puntos-guía para investigar a los nacionalismos y posiblemente a todos los movimientos culturales: en primer lugar es necesario tener en cuenta las influencias culturales de los autores próximos a analizar, pues ese punto nos indicará las fuentes desde las cuales replantearon las ideas recibidas en un discurso propio y nuevo. En segundo lugar, es evidente e inherente al trabajo de cualquier historiador valorar el contexto de época para dejar en evidencia los cambios que sufrieron en sus convicciones los autores analizados. Es contrario a la correcta metodología de la investigación en historia desentenderse de los vaivenes ideológicos de los intelectuales, siempre influidos por sucesos históricos que, por lo general, son trascendentales. En tercer lugar, y en relación con el punto anterior, se deben desarticular las esquematizaciones y tratar de prescindir de ellas, pues lo correcto para filiar ideológicamente a un autor es reconstruir su pasado intelectual, ya que de esta forma se entenderá por completo su pensamiento y se desnaturalizará su participación política más trascendental. Dicho punto es importante si tenemos en cuenta el uso político de la historia que han realizado muchos partidos -no solo la UCR, sino también el peronismo- tratando de ocultar las filiaciones políticas previas de sus más relevantes figuras. En último y cuarto lugar, aunque sirva como un punto solo aplicable al análisis de los nacionalismos, se debe tener en cuenta la idea de nación que guardaban los intelectuales -porque desde allí parten sus reivindicaciones nacionalistas- $\mathrm{y}$, en especial, el lugar que otorgaban a los inmigrantes en el país y al Estado en la economía, factores importantes para precisar cualquier posición ideológica.

\footnotetext{
${ }^{81}$ De hecho, Julio Irazusta tradujo algunos trabajos de Burke. Véase Edmund Burke, Reflexiones sobre la Revolución Francesa y otros escritos (Buenos Aires: Dictio, 1980). Véase además: Fernando Devoto y Nora Pagano, Historia de la historiografía argentina, 228. Terán destacó las influencias en muchos revisionistas del nacionalismo elitista las "marcas explícitas de entronque con la vieja línea del pensamiento reaccionario y conservador" basadas en los escritos de Edmund Burke, autor de 1790, crítico del proceso revolucionario francés y de los males de la modernidad en la política. Véase Óscar Terán, Historia de las ideas, 232; y Michael Goebel, La Argentina partida, 67.
}

ISSN 2174-4289 


\section{Profile}

Gonzalo Rubio García es licenciado en Historia Universidad de Buenos Aires (1915) donde ha defendido en 2016 una tesis titulada El pensamiento de Raúl Scalabrini Ortiz dirigida por el profesor José Carlos Chiaramonte (UBA/CONICET). En la actualidad prepara varios artículos sobre el nacionalismo argentino y realiza una tesis doctoral sobre el revisionismo histórico argentino y sus antecedentes intelectuales.

Gonzalo Rubio García graduated in History at the University of Buenos Aires (2015) with a thesis entitled The thought of Raúl Scalabrini Ortiz supervised by Professor José Carlos Chiaramonte (UBA/CONICET) (2016). He is currently preparing articles on Argentine nationalism and working for his $\mathrm{PhD}$ on the Argentina historical revisionism and its intellectual backgrounds.

Fecha de recepción: 8 de abril de 2017.

Fecha de aceptación: 22 de mayo de 2017.

Publicación: 30 de junio de 2017.

Para citar este artículo: Gonzalo Rubio García, "Los nacionalismos argentinos: un acercamiento al debate historiográfico en torno a sus figuras de la década de 1930", Historiografías, 13 (enero-junio, 2017): pp. 74-94. http://www.unizar.es/historiografias/historiografias/numeros/13/rubio.pdf 